\title{
Engraftment of mesenchymal stem cells into dystrophin-deficient mice is not accompanied by functional recovery
}

\author{
Eun Ji Gang ${ }^{a}$, Radbod Darabi ${ }^{a, c}$, Darko Bosnakovski ${ }^{a, c}$, Zhaohui Xu ${ }^{a}$, Kristine E. Kamm ${ }^{b}$, \\ Michael Kyba ${ }^{a, c}$, Rita C.R. Perlingeiro ${ }^{a, c, *}$ \\ ${ }^{a}$ Department of Developmental Biology, University of Texas Southwestern Medical Center, 5323 Harry Hines Blvd, Dallas 75390-9133, Texas, USA \\ ${ }^{\mathrm{b}}$ Department of Physiology, University of Texas Southwestern Medical Center, 5323 Harry Hines Blvd, Dallas 75390-9133, Texas, USA \\ ${ }^{c}$ Lillehei Heart Institute, Department of Medicine, University of Minnesota, 312 Church St. S.E., Minneapolis 55455, Minnesota, USA
}

\section{A R T I C L E I N F O R M A T I O N}

Article Chronology:

Received 16 February 2009

Revised version received 5 May 2009

Accepted 6 May 2009

Keywords:

Mesenchymal stem cells

Pax3

Muscle differentiation

Dystrophin

Transplantation

Tumors

\begin{abstract}
A B S T R A C T
Mesenchymal stem cell preparations have been proposed for muscle regeneration in musculoskeletal disorders. Although MSCs have great in vitro expansion potential and possess the ability to differentiate into several mesenchymal lineages, myogenesis has proven to be much more difficult to induce. We have recently demonstrated that Pax3, the master regulator of the embryonic myogenic program, enables the in vitro differentiation of a murine mesenchymal stem cell line (MSCB9-Pax3) into myogenic progenitors. Here we show that injection of these cells into cardiotoxin-injured muscles of immunodeficient mice leads to the development of muscle tumors, resembling rhabdomyosarcomas. We then extended these studies to primary human mesenchymal stem cells (hMSCs) isolated from bone marrow. Upon genetic modification with a lentiviral vector encoding PAX3, hMSCs activated the myogenic program as demonstrated by expression of myogenic regulatory factors. Upon transplantation, the PAX3-modified MSCs did not generate rhabdomyosarcomas but rather, resulted in donor-derived myofibers. These were found at higher frequency in PAX3-transduced hMSCs than in mock-transduced MSCs. Nonetheless, neither engraftment of PAX3-modified or unmodified MSCs resulted in improved contractility. Thus these findings suggest that limitations remain to be overcome before MSC preparations result in effective treatment for muscular dystrophies.
\end{abstract}

(C) 2009 Elsevier Inc. All rights reserved.

\section{Introduction}

Muscular dystrophies are genetically and clinically heterogeneous disorders characterized by progressive weakness and degeneration of the skeletal muscles that control movement. Among these disorders, Duchenne muscular dystrophy (DMD) is the most common, affecting 1 out of every 3500 live born boys. DMD is an $\mathrm{X}$-linked recessive muscle disorder caused by mutations in the dystrophin gene, resulting in the absence of dystrophin in skeletal muscle and other tissues [1-3]. Current treatment involves pharmacological control of inflammation which ameliorates symptoms but does not cure or extend the life expectancy of affected patients.

Bone marrow transplantation is at the vanguard of cellular therapies and it has been widely and successfully used in clinics for the treatment of congenital, malignant, and degenerative diseases

\footnotetext{
* Corresponding author. Lillehei Heart Institute, University of Minnesota, 4-124 Nils Hasselmo Hall, 312 Church St. S.E., Minneapolis 55455, MN, USA. Fax: +612 6248118.

E-mail address: perli032@umn.edu (R.C.R. Perlingeiro).
}

0014-4827/\$ - see front matter @ 2009 Elsevier Inc. All rights reserved. doi:10.1016/j.yexcr.2009.05.009 
of the bone marrow (BM). During the last decade, a flurry of controversial studies has exploited the plasticity of bone marrow cells and their therapeutic potential on non-hematological disorders [4-9], including muscular dystrophies [10-15]. Ferrari et al. were the first to document that BM cells had the ability to migrate from the circulation into cardiotoxin-injured muscles, and participate in skeletal muscle regeneration. These results were further confirmed by several investigators that applied BM transplantation to $m d x$ mice, an animal model for DMD [11-13]. Despite the initial enthusiasm, quantification of engraftment revealed that the number of donor-derived myofibers in transplanted mice was rather low $(<1 \%)$ [11,16], leading to questioning of the biological and therapeutic relevance of these findings. As observed with other cell lineages, it is possible that the low level engraftment observed in muscle tissues results solely from cell fusion rather than from BM plasticity [17-22]. It is also plausible to assume that a cell population with limited myogenic potential was transplanted in these experiments, given that most reports described above made use of whole BM, which is highly heterogeneous.

BM is well-known as a source of hematopoietic stem cells, but it also contains a stromal cell population, known as mesenchymal stem cells or marrow stromal cells (MSCs), that is endowed with the ability to self-renew and differentiate into multiple mesenchymal lineages, including bone, fat, cartilage, and connective tissue [23-25]. Experimental approaches involving induction of MSCs with 5-azacytidine [26], co-culture of MSCs with myoblasts [27] or myoblast-conditioned medium [28], and more recently activated Notch [29], suggest that skeletal muscle progenitors can also be obtained from MSCs. Although MSCs represent less than $0.01 \%$ of the BM mononuclear cell fraction, they are easily expanded in vitro and thus, amenable to genetic manipulation. We have recently demonstrated that by overexpressing Pax3, the master regulator of the myogenic program, a mesenchymal stem cell line can be specifically reprogrammed to differentiate into the myogenic lineage [30]. These results led us to test their myogenic potential in vivo as well as to investigate whether PAX3 is able to reprogram primary human MSCs, and whether resulting reprogrammed cells are capable of promoting muscle regeneration in vivo.

\section{Materials and methods}

\section{MSC isolation and culture}

Human BM samples were purchased from Cambrex. hMSCs were isolated according to previously described protocol [25]. Briefly, cells were separated from 10 to $20 \mathrm{ml}$ of marrow diluted with four volumes of Minimum Essential Medium Alpha Medium ( $\alpha$-MEM, Invitrogen) containing 10\% FBS (Atlanta Biologicals) by centrifugation at $900 \mathrm{~g}$ for $15 \mathrm{~min}$. Cells were washed with cold Dulbecco's phosphate-buffered saline (DPBS) once and plated at $2 \times 10^{6}$ cells per $\mathrm{cm}^{2}$ in MSC expansion medium consisting of low-glucose DMEM supplemented with 40\% MCDB-201 (Invitrogen), 10\% FBS, $1 \times$ insulin-transferrin-selenium (ITS; Sigma), $1 \times$ linoleic-acid-bovineserum-albumin (Sigma), $10^{-8} \mathrm{M}$ dexamethasone (Sigma), $10^{-4} \mathrm{M}$ ascorbic acid 2-phosphate (Sigma), $50 \mathrm{U} / \mathrm{ml}$ penicillin/streptomycin (Invitrogen), $10 \mathrm{ng} / \mathrm{ml}$ of hPDGF-BB (Peprotech), and $10 \mathrm{ng} / \mathrm{ml}$ of hEGF (Peprotech). After $72 \mathrm{~h}$ of culture, suspended cells were removed and replaced with fresh media. Medium was changed every 3 days thereafter. hMSCs grew as colonies which were detached with $0.1 \%$ trypsin-EDTA and sub-cultured at a density of $4-8 \times 10^{3}$ cells per $\mathrm{cm}^{2}$.

\section{Lentiviral infection and purification of $\mathrm{GFP}^{+}$mesenchymal stem cells}

The multiple cloning site (BglII-EcoRI-NotI-SalI) of pBS was PCRamplified and cloned into pGEM-T (Promega) to generate pGEMBS. pGEMiresGFP was generated by inserting $1.3 \mathrm{~kb}$ Sall-digested iresGFP fragment from pMSCViresGFP [31] into the Sall site of pGEM-BS. The lentiviral vector PSAM was generated by inserting a $1.3 \mathrm{~kb}$ BglII/Ndel-digested and filled-in iresGFP fragment from pGEMiresGFP into the BamHI/EcoRI-digested and filled-in cloning site of FUGW [32]. We refer to this vector as PSAM. Lentiviral vector pSAM-Pax3 was created by sub-cloning the cDNA for Pax3 obtained from pSPORT-Pax3 (BC048699, Open Biosystems) into pSAM as an EcoR I/BamH I digested and BamH I filled-in fragment. This vector was co-transfected with packaging and coat protein constructs $\Delta 8.91$ and pVSVG, respectively, into 293T cells using the FuGENE 6 transfection reagent (Roche) as recommended by the manufacturer. Virus-containing supernatant was collected $48 \mathrm{~h}$ after transfection and filtered through a $0.45 \mu \mathrm{m}$ filter before use. MSC cells were suspended in $3 \mathrm{ml}$ of viral supernatant containing $10 \mathrm{ng} / \mathrm{ml}$ hPDGF-BB, $10 \mathrm{ng} / \mathrm{ml} \mathrm{hEGF}$, and $8 \mu \mathrm{g} / \mathrm{ml}$ polybrene (Sigma). Cells were then transferred to 6-well plates and centrifuged at $2500 \mathrm{rpm}$ for $90 \mathrm{~min}$ at $33{ }^{\circ} \mathrm{C}$ on a Hettich centrifuge. After a $4 \mathrm{~h}$-incubation at $37{ }^{\circ} \mathrm{C}$ with $5 \% \mathrm{CO}_{2}$ in air, supernatant was removed and changed with fresh MSC expansion medium as described above. Two days following infection, cells were harvested and sorted based on the gating of $\mathrm{GFP}^{+}$on the FITC channel. GFP ${ }^{+}$hMSCs were maintained in MSC expansion medium for further in vitro and in vivo studies.

Table 1 - Specific human sense and anti-sense primers for quantitative real-time PCR analysis.

\begin{tabular}{lccc} 
Gene & Primer sense sequence & Primer anti-sense sequence & Product size (bp) \\
\hline hMYOD & CACTCCGGTCCCAAATGTAG & TTCCCTGTAGCACCACACAC & 180 \\
hMYF5 & GATTCACAGCCTCGAACTCC & TGAAGCCTTCTCGTCCTGT & 125 \\
hMYOGENIN & TAGCAGGGGCTCCTAAGC & CTCTGGTCCCTGCTTTACC & 193 \\
hMHC & CCAAGGACCCTTCAAGATCA & 172 \\
$h$ ATGPDH & CATCTTCCAGGAGCGAGAT & TGCAAATGAGCCCCAGCCTT & 114 \\
\hline
\end{tabular}

MHC, myosin heavy chain type IIb. 
A
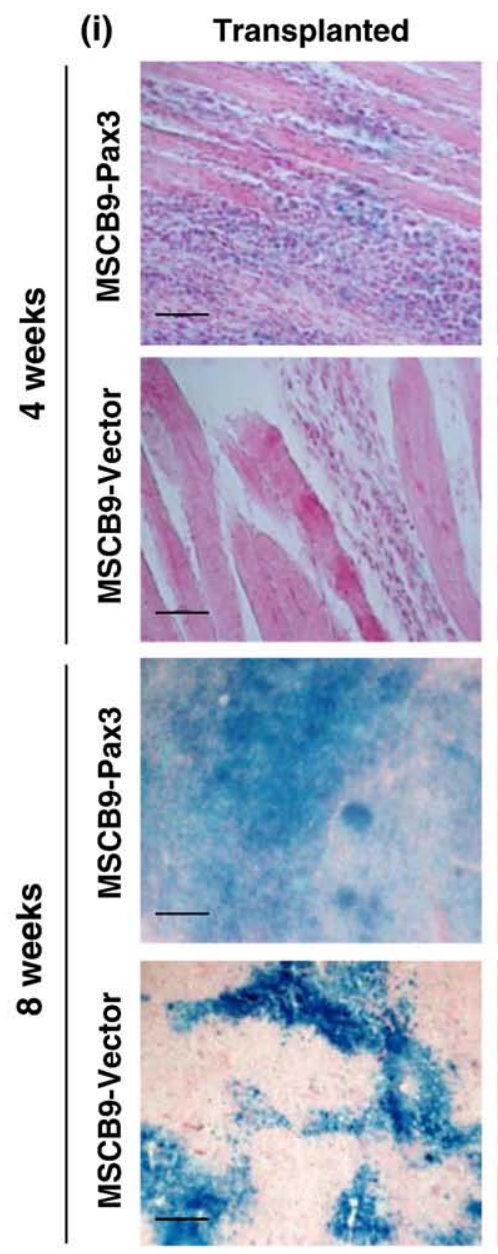

Contralateral
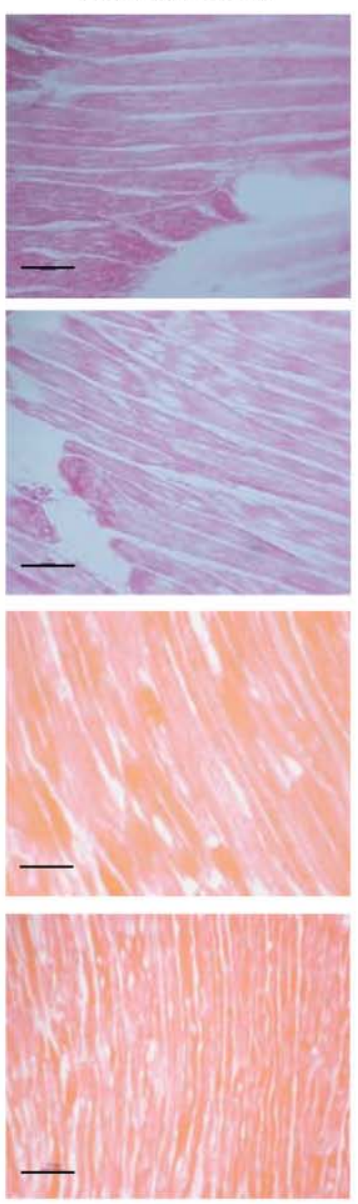

(ii)
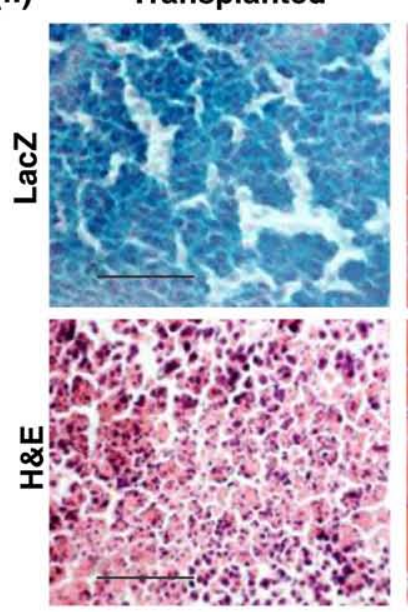

\section{Contralateral}
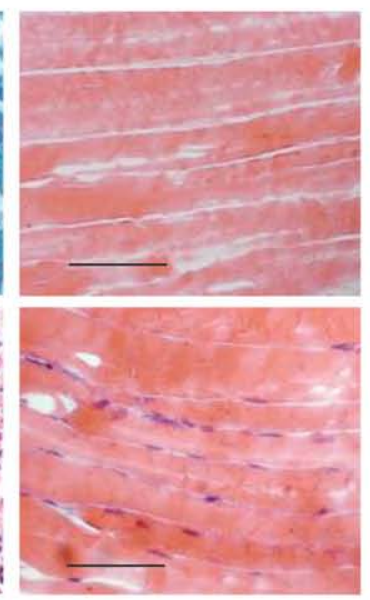

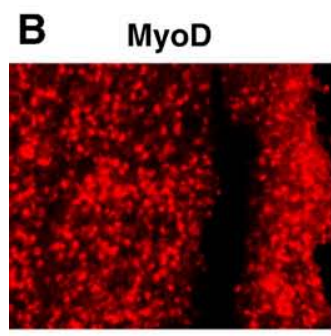

Myogenin

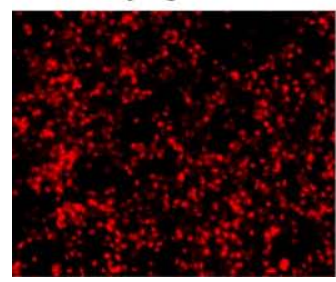

GFP

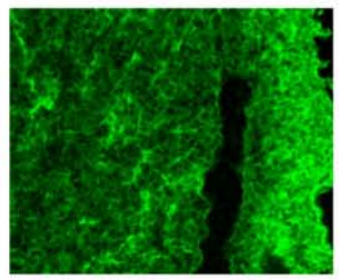

GFP

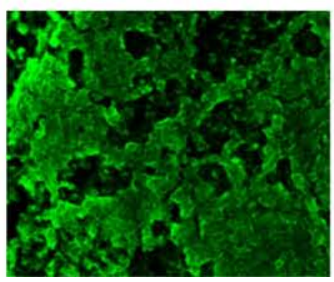

MyoD/GFP

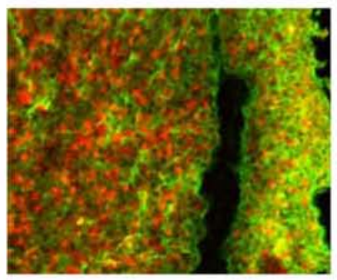

Myogenin/GFP

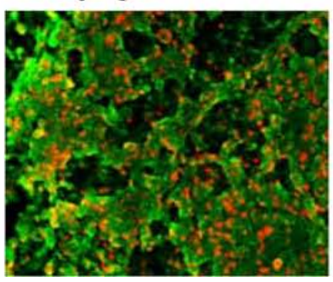

DAPI

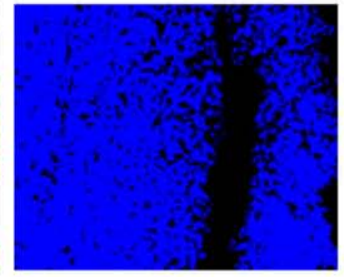

DAPI

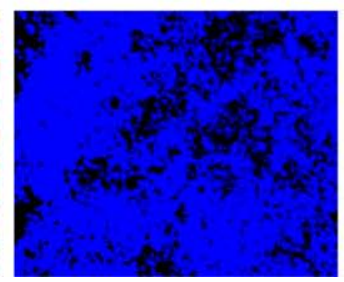

MyoD/DAPI

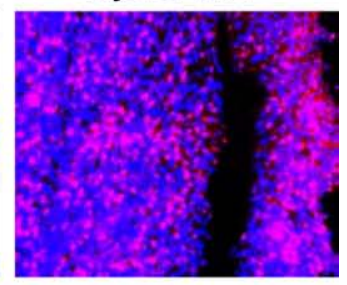

Myogenin/DAPI

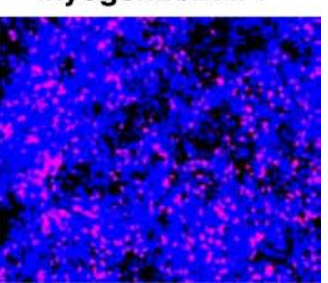

Fig. 1 - Development of rhabdomyosarcoma following the transplantation of MSCB9-Pax3 cells. (A) MSCB9-Pax3 or MSCB9-Vector (MSCB9-Vec) cells were injected into cardiotoxin-injured TA muscles of $\operatorname{Rag}^{-/-} \gamma \mathrm{c}^{-/-}$mice. Contralateral TA muscles were used as controls. Engrafted cells $\left(\mathrm{LacZ}^{+}\right.$) were detected at 4-week (i. upper two panels) and 8-week post-transplantation (i. lower two panels) by X-gal staining. These latter samples were also examined by H\&E staining (ii. lower panel). (B) Immunofluorescent staining of muscle cryosections at 4 weeks post-transplantation for MyoD and Myogenin (staining with Cy3 in red); direct GFP signal (green); merge for GFP and MyoD or Myogenin (cells expressing both are seen in yellow/orange); DAPI staining in blue, and merge

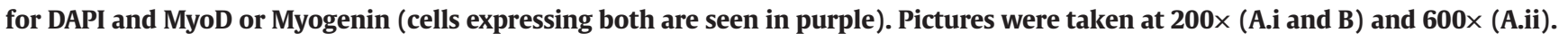
Scale bar is $100 \mu \mathrm{m}$. 


\section{Western blot}

Western blots were performed using the following antibodies: mouse monoclonal anti-Pax3 ( $\mathrm{R}$ and D Systems), and mouse monoclonal anti-actin (Sigma).

\section{FACS analysis of $\mathrm{GFP}^{+}$cells}

Pax3- or Vector control-transduced MSCs at passage 2 were trypsinized with $0.1 \%$ Trypsin-EDTA and washed with blocking buffer (DPBS with 2\% FBS), suspended in the same buffer containing $0.25 \mu \mathrm{g} / 10^{6}$ cells of Fc block (Pharmingen) and placed on ice for 5 min. Allophycocyanin (APC)- or Phycoerythrin (PE)conjugated mouse antibodies to human markers including CD73, CD44, CD90, CD45, CD34 (Pharmingen), CD105 (Serotec), and
CD56 (NCAM; BioLegend) were added at $1 \mu \mathrm{g} / 10^{6}$ cells and incubated at $4{ }^{\circ} \mathrm{C}$ for 20 min before washing with blocking buffer. As matching isotype controls, APC- or PE-conjugated mouse antiIgG antibodies (Pharmingen) were used. Cells were then analyzed on FACS Aria (Becton-Dickinson) after addition of propidium iodide (Pharmingen) to exclude dead cells.

\section{Myogenic induction}

For myogenic differentiation, cells were cultured for up to 3 weeks in several muscle inductive conditions as follows: LG-DMEM supplemented with 10\% FBS, bFGF (10 ng/ml; Peprotech), neuregulin (200 ng/ml; Peprotech), hPDGF-AA (5 ng/ml; Peprotech), and forskolin (FSK, $5 \mu \mathrm{M}$; Calbiochem); LG-DMEM supplemented with $2 \%$ horse serum (HS, Atlanta Biologicals) and $1 \times$ ITS,
A
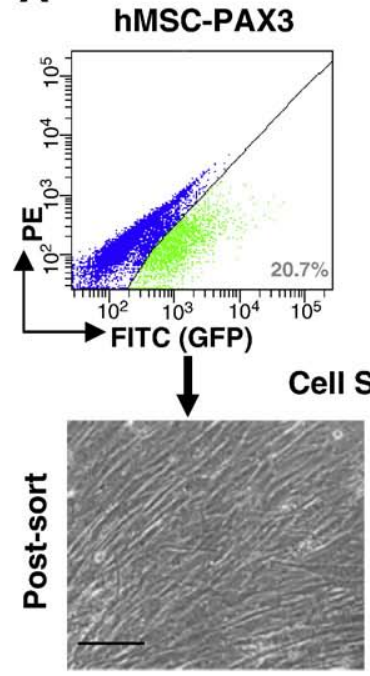

C

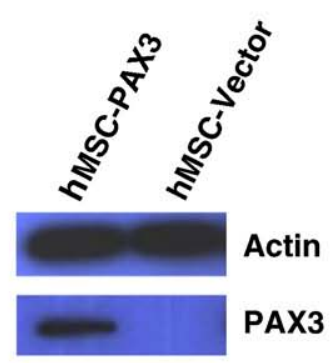

hMSC-Vector

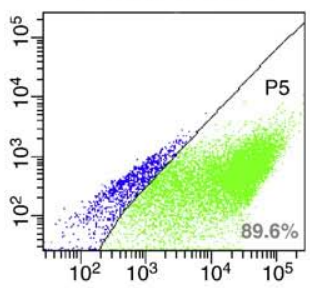

$\downarrow$

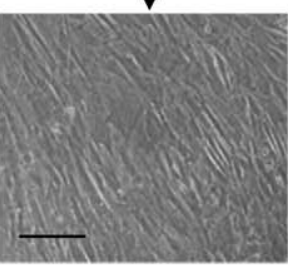

B
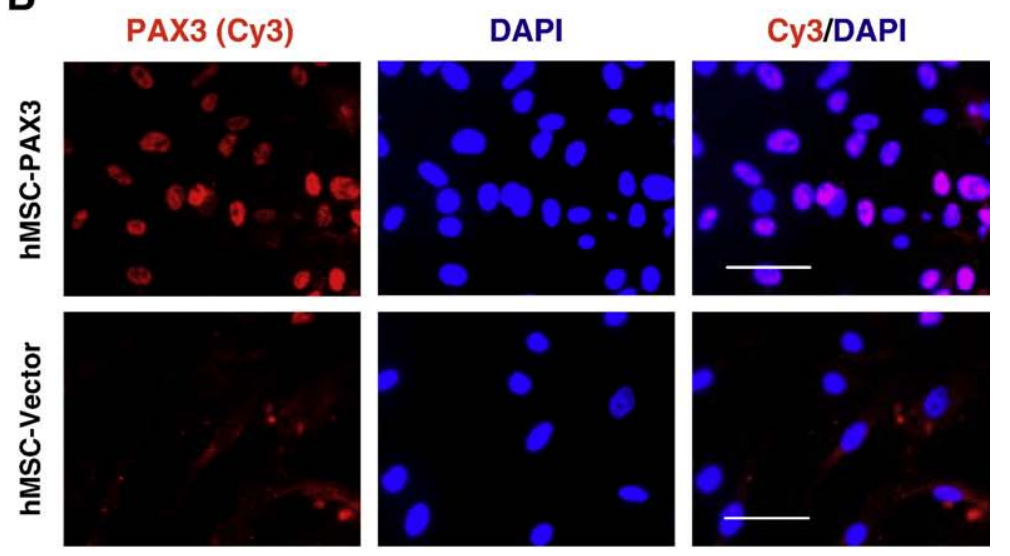

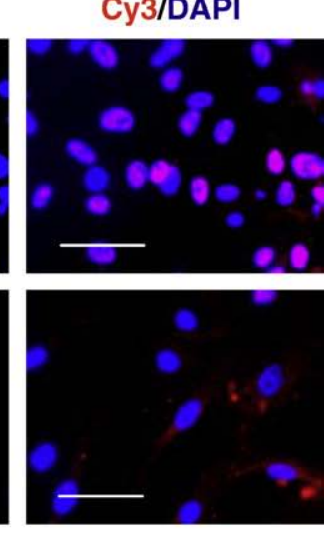

\section{Суз/DAPI}

MYOD
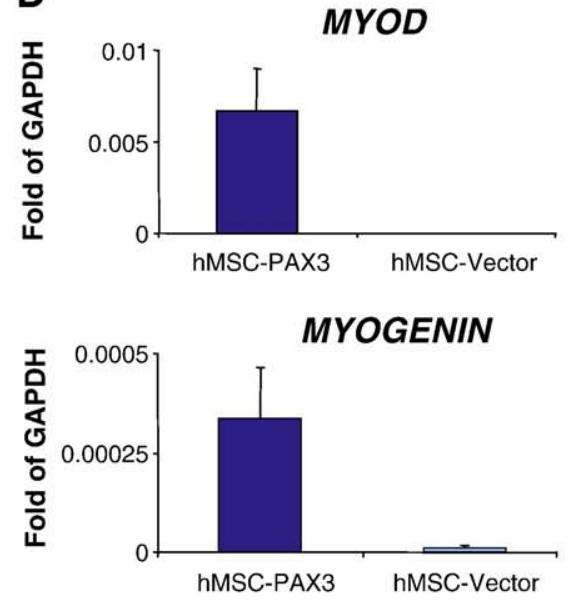
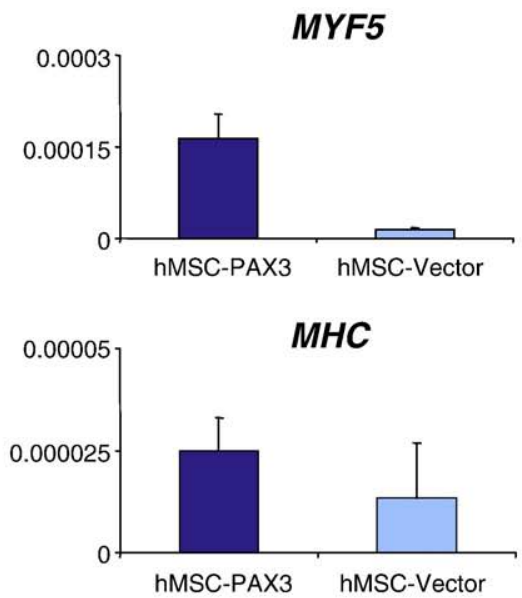

Fig. 2 - Activation of the myogenic program in PAX3-expressing hMSCs. (A) FACS profile for GFP expression and morphology of sorted cells in hMSCs transduced with PAX3 or vector control. GFP is indicated on $x$ axis, and autofluorescence on $y$ axis. GFP ${ }^{+}$cells were sorted according to represented gates and cultured in MSC expansion medium. Pictures were taken at 200×. Scale bar is $100 \mu \mathrm{m}$. (B) Immunofluorescence for PAX3 (Cy3, red) in hMSC-PAX3 and hMSC-Vector cells. DAPI staining in blue. Pictures were taken at 400x. Scale bar is $100 \mu \mathrm{m}$. (C) Western blot analysis for PAX3 in hMSC-PAX3 and hMSC-Vector cells. (D) Gene expression analysis by real-time PCR for myogenic-specific markers in hMSC-PAX3 and hMSC-Vector cells. Transcripts were normalized to GAPDH ( $y$ axis). Error bars indicate standard errors from 3 independent experiments. 
and LG-DMEM supplemented with 10\% FBS and 5-azacytidine (5 $\mu \mathrm{M}$; Sigma); as controls, we also evaluated cells that were maintained in MSC expansion medium (with and without growth factors) and $\alpha$-MEM supplemented with 16.5\% FBS.

\section{RNA isolation and real-time quantitative PCR analysis}

Total RNA was isolated using Trizol (Invitrogen) as recommended by the manufacturer. First strand cDNA was produced using Superscript
II reverse transcriptase (Invitrogen) with Oligo dT. For gene expression assays, $2 \mu \mathrm{l}$ of cDNA from reverse-transcription of total RNA as a template was amplified using SYBR Green Master Mix reagent (Applied Biosystems) and 7500 Real-Time PCR System (Applied Biosystem). The muscle-specific primers for human MYOD, MYF5, MYOGENIN, MHC, GAPDH and PCR product sizes are described in Table 1. For PAX3, a probe set was acquired from Applied Biosystems. The data are reported as a ratio of absolute mRNA copy number of each specific gene to the absolute copy number of GAPDH.
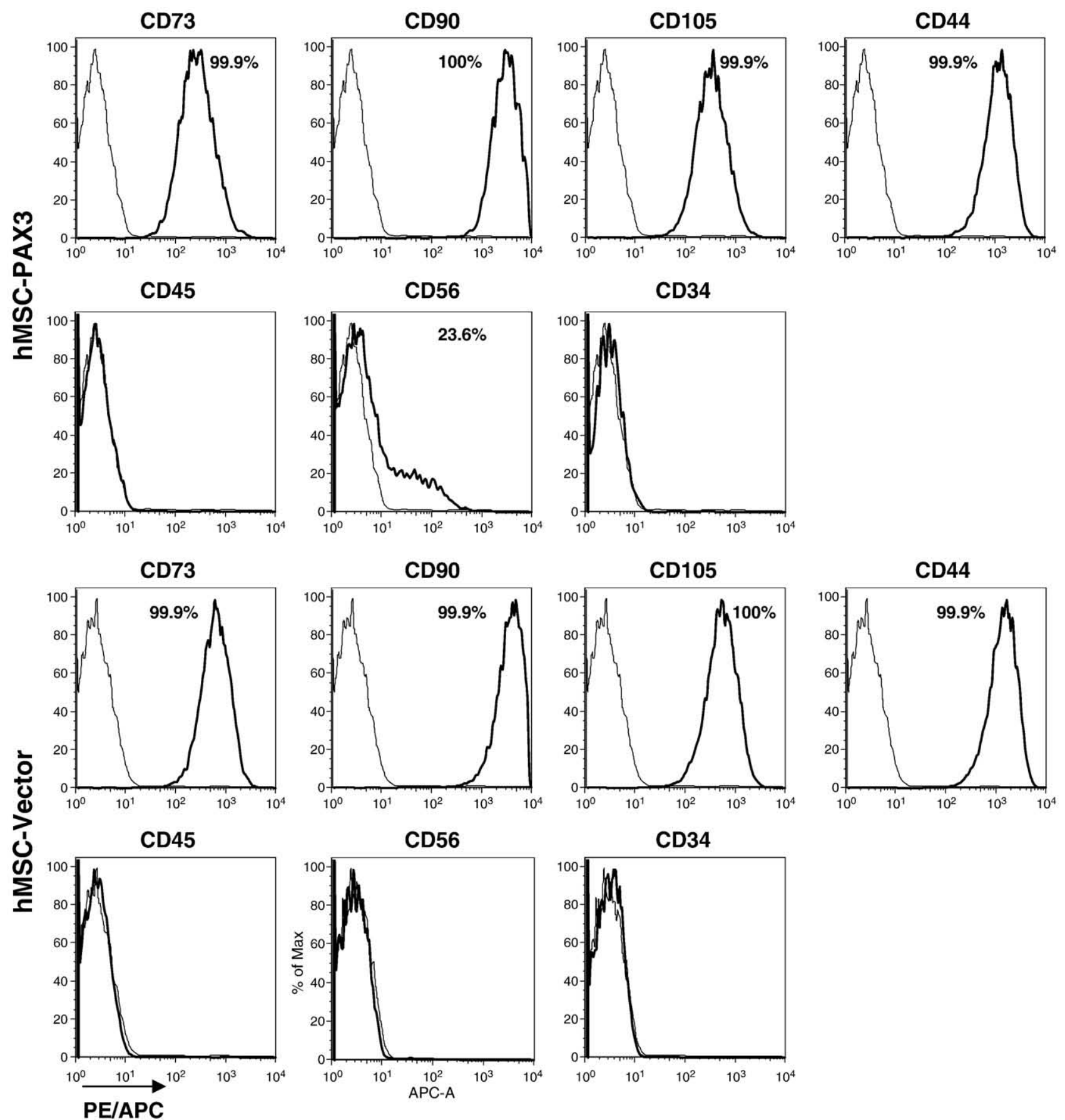

Fig. 3 - Characterization of hMSCs-PAX3. Flow cytometric analyses of hMSC-PAX3 and hMSC-Vector cells at passage 2. Plots show isotype or secondary control staining profile (thin line) versus specific antibody staining profile (thick line). Percentages represent the fraction of cells that express a given surface antigen. This analysis was performed twice. 


\section{Animals and transplantation}

Animal experiments were carried out according to protocols approved by the UT Southwestern Medical Center Institutional Animal Care and Use Committee and met US National Institutes of Health guidelines for the humane care of animals. Six- to eightweek-old Rag2 $2^{-1-} \gamma \mathrm{c}^{-/-}$immunodeficient mice (Taconic laboratories) and $\mathrm{C} 57 \mathrm{BL} / 10 \mathrm{ScSN}-\mathrm{Dmd} \mathrm{m}^{\mathrm{mdx} / \mathrm{j}}$ (X-linked muscular dystrophy; Jackson Laboratory) were used as recipients for the transplantation study. One day before transplantation, $75 \mu \mathrm{l}$ of cardiotoxin (10 $\mu \mathrm{M}$, Sigma) was injected into both tibialis anterior (TA) muscles of each mouse to induce muscle injury. $24 \mathrm{~h}$ later, Pax3or Vector-transduced MSCB9 or primary human mesenchymal stem cells were injected $\left(1 \times 10^{6}\right.$ in $50 \mu \mathrm{l}$ of phosphate-buffered saline) into the right TA muscles of each group. As control, $50 \mu \mathrm{l}$ of PBS were injected in the left TA muscle of animals. For immuno-suppression, $m d x$ mice received a daily dose of $5 \mathrm{mg} / \mathrm{kg}$ FK 506 (Tacrolimus; Sigma) intra-peritoneally (IP) from the day before cell injection until the time of euthanasia (4 weeks after transplantation).

\section{Immunofluorescent staining of cultured cells and tissue sections}

TA muscles were isolated, embedded in OCT compound (TissueTek) and immediately frozen in isopentane cooled in liquid nitrogen. Serial cryostat sections $(8-12 \mu \mathrm{m})$ were collected. For immunofluorescence staining, cells cultured on slides and tissue cryosections were fixed using $4 \%$ paraformaldehyde/PBS (acetone was applied for dystrophin staining), permeabilized with $0.5 \%$ Triton X-100 (Sigma), and blocked with 10\% goat serum (or $3 \%$ BSA), and then incubated with primary antibodies including GFP (Molecular Probes), Pax3 (R and D Systems), MyoD (both from BD Biosciences), MHC (Developmental Studies Hybridoma Bank), and dystrophin (Abcam). Cy2 and Cy3 (Jackson Immunoresearch Laboratories) secondary antibodies were used. DAPI (4,6-diamidino-2-phenylindole; Fluka) was used to counter-stain nuclei. Nonspecific isotype control antibodies were used as negative controls. X-gal staining was performed for detection of $\mathrm{LacZ}^{+}$cells. Sections were fixed with $0.2 \%$ glutaraldehyde in washing buffer
A
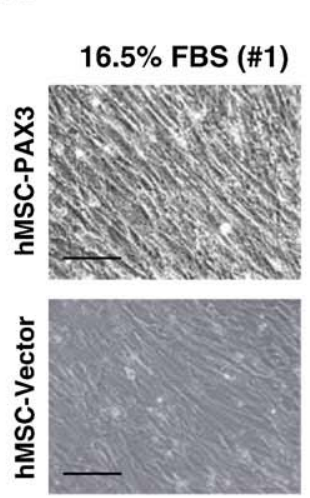

$10 \%$ FBS, bFGF, neuregulin, PDGF-AA,

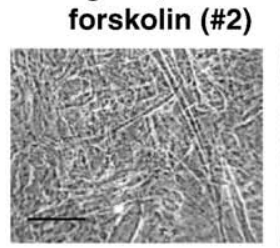

$2 \%$ HS (\#3)
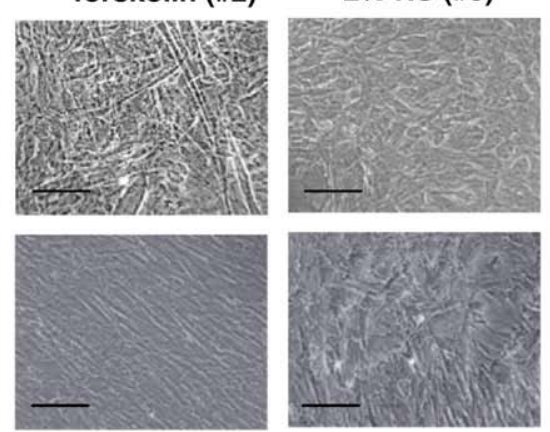
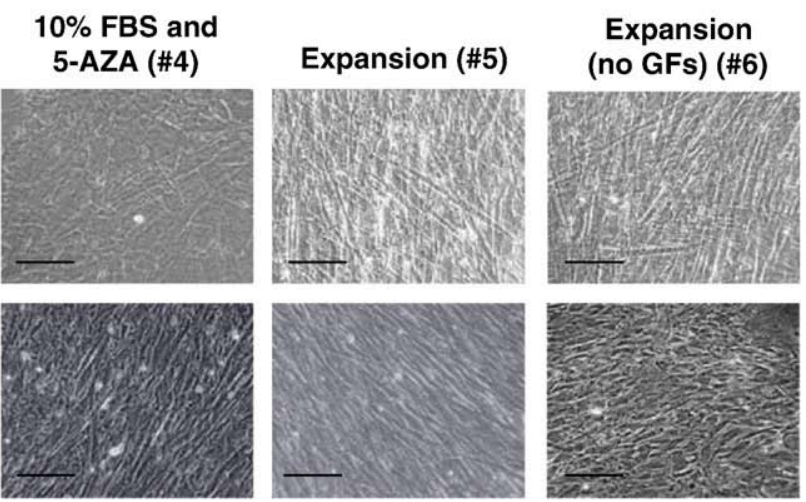

B

PAX3
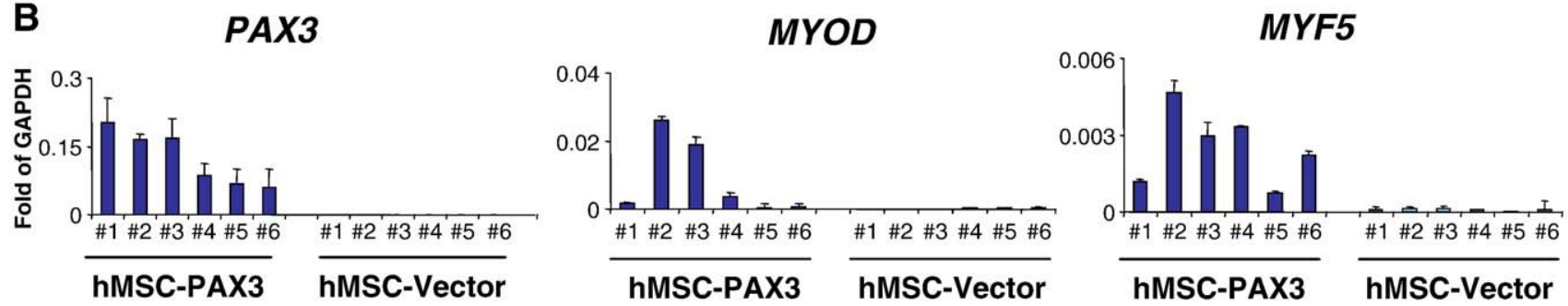

MYOGENIN
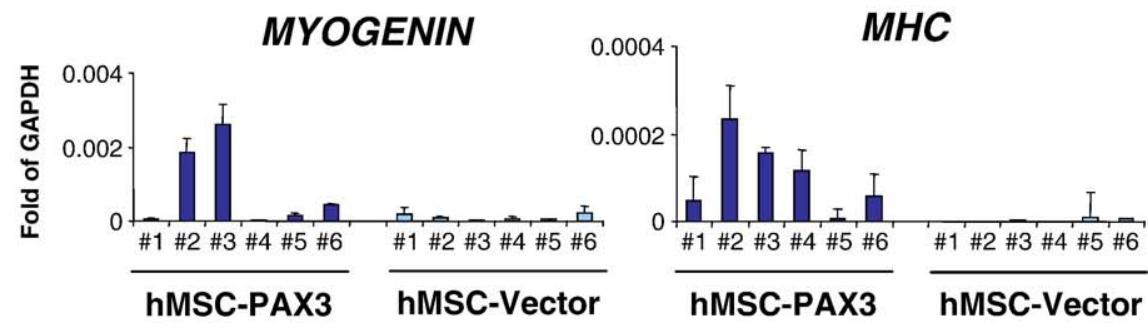

Fig. 4 - Effects of several induction protocols on the myogenic differentiation of hMSCs. (A) Representative morphologies of hMSC-PAX3 and hMSC-Vector cells after 4 weeks under several myogenic induction protocols and, (B) their respective gene expression profile by real-time PCR analysis. Transcripts were normalized to GAPDH ( $y$ axis). Error bars indicate standard errors from 4 independent experiments. (C) Immunofluorescent staining for MYOD and MHC (Cy3, red) in hMSC-PAX3 and hMSC-Vector cells grown under expansion (\#1) or myogenic induction (\#2, bFGF and neuregulin) medium. Cells are co-stained with DAPI (blue). Arrows indicate nuclei within the myotube. All photographs were taken at $200 \times$. Scale bar is $100 \mu \mathrm{m}$. (D) Percentage of MYOD ${ }^{+}$and MHC $^{+}$in these hMSC-PAX3 cultures. Error bars indicate standard errors from 2 independent experiments. 
C
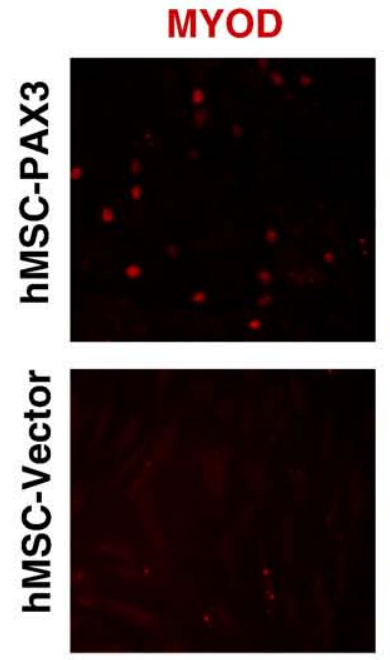

$16.5 \%$ FBS (\#1)
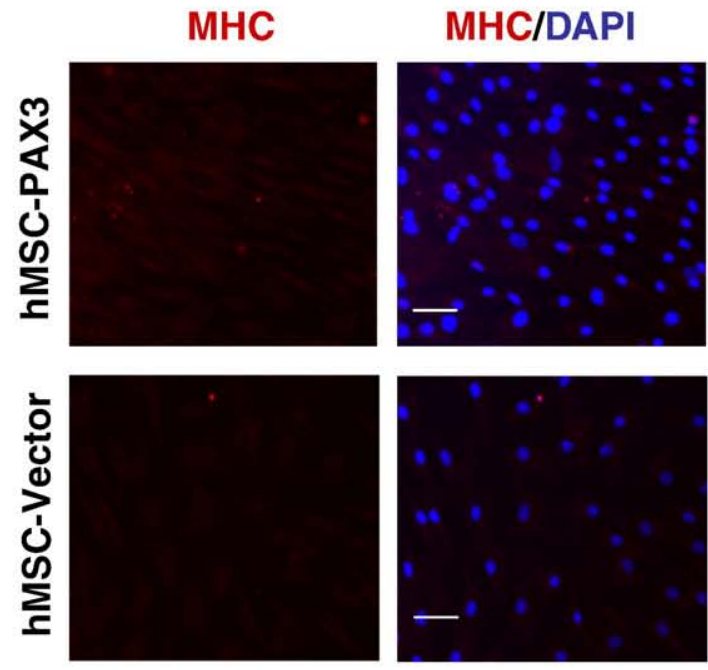

$16.5 \%$ FBS (\#1)
MYOD/DAPI
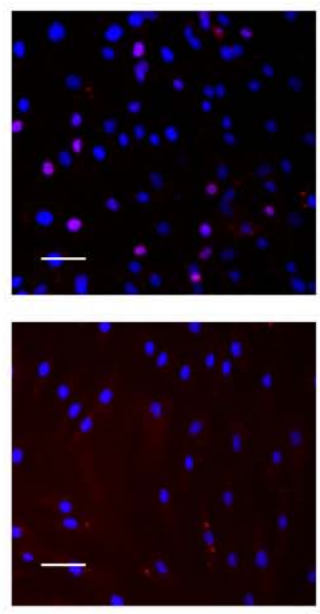

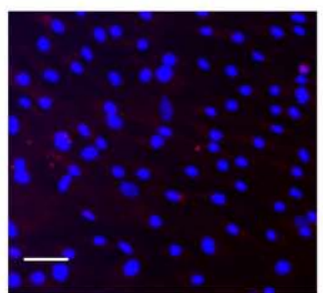

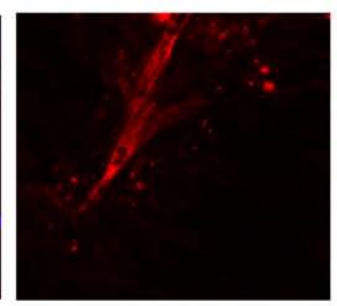

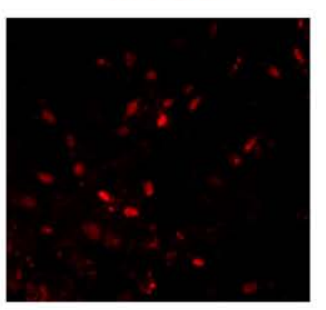

\section{MYOD/DAPI}
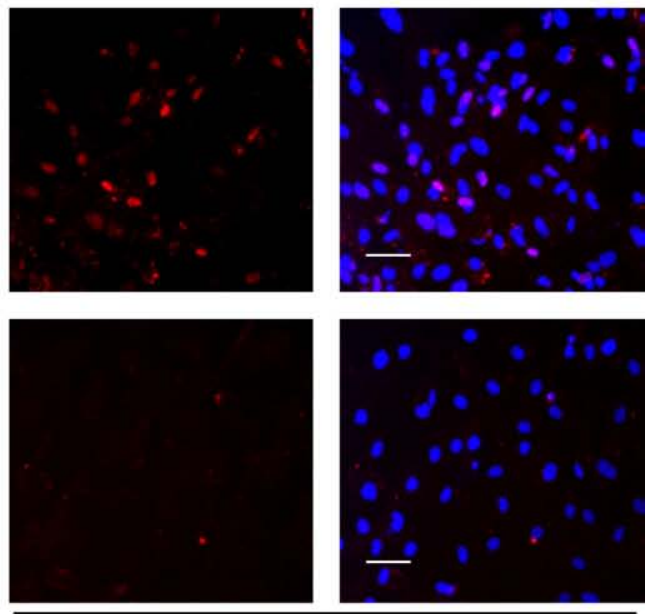

bFGF/Neuregulin (\#2)
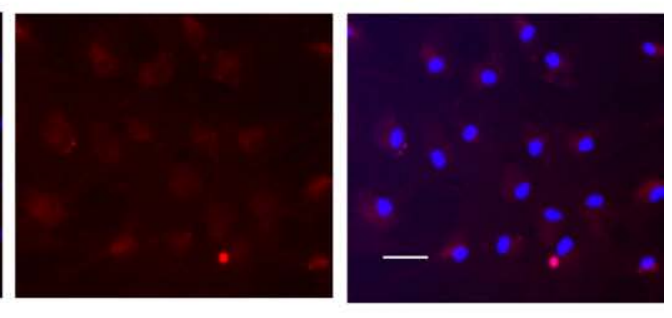

bFGF/Neuregulin (\#2)

D

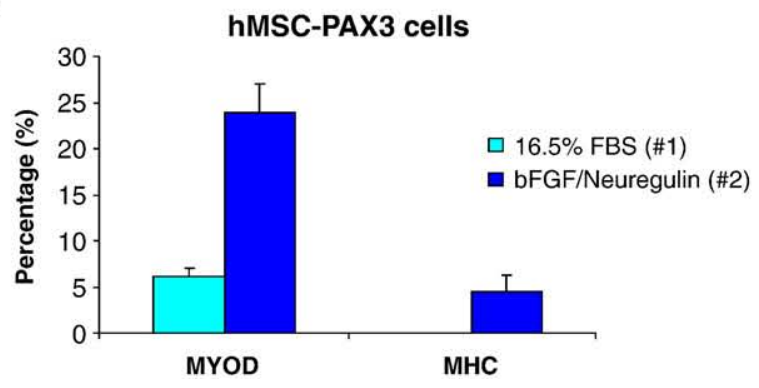

Fig. 4 (continued).

(5 mM EGTA, 2 mM MgCl $2,0.1$ M sodium phosphate buffer, pH 7.3), rinsed with washing buffer and incubated overnight at $37{ }^{\circ} \mathrm{C}$ in X-gal solution (2 mM 5-bromo-4-chloro-3-indolyl-b-D-galactopyranoside/dimethyl-formamide, $4 \mathrm{mM} \mathrm{K}_{3} \mathrm{Fe}(\mathrm{CN})_{6}, 4 \mathrm{mM}$ K4Fe $(\mathrm{CN})_{6} \cdot 3 \mathrm{H}_{2} \mathrm{O}$ and $1 \mathrm{mM} \mathrm{MgCl}$ in washing buffer. Sections were then counterstained with Hematoxylin and Eosin (H\&E) staining, as described [33].

\section{Muscle preparation for mechanical studies}

For the measurement of contractile properties, the mice were anaesthetized with sodium pentobarbitone ( $70 \mathrm{mg} / \mathrm{kg}$ I.P.) and intact tibialis anterior (TA) muscles were dissected and placed in an experimental organ bath filled with mammalian Ringer solution containing (mM): $\mathrm{NaCl} 120.5 ; \mathrm{NaHCO}_{3} 20.4$; glucose 10; $\mathrm{KCl}$ 4.8; $\mathrm{CaCl}_{2}$ 
1.6; $\mathrm{MgSO}_{4} 1.2 ; \mathrm{NaH}_{2} \mathrm{PO}_{4} 1.2$; pyruvate 1.0 , adjusted to $\mathrm{pH}$ 7.4. The chamber was perfused continuously with $95 \% \mathrm{O}_{2}-5 \% \mathrm{CO}_{2}$ and maintained at a temperature of $25{ }^{\circ} \mathrm{C}$. The muscles were stimulated by an electric field generated between two platinum electrodes placed longitudinally on either side of the muscle (square wave pulses $25 \mathrm{~V}$, $0.2 \mathrm{~ms}$ in duration, $150 \mathrm{~Hz}$ ). Muscles were adjusted to the optimum length ( $L o$ ) for the development of isometric twitch force and a $5 \mathrm{~min}$ recovery period was allowed between stimulations. Optimal muscle length (Lo) and stimulation voltage (25 V) were determined from micromanipulation of muscle length and a series of twitch contractions that produced maximum isometric twitch force. In brief, after determination of optimal muscle length (Lo) and measurement of maximum isometric tetanic force, total muscle fiber cross-sectional area (CSA) was calculated by dividing muscle mass (milligram) by the product of fiber length (millimeter) and $1.06 \mathrm{mg} / \mathrm{mm}^{3}$, the density of mammalian skeletal muscle. Specific force $\left(S F_{0}\right)$ was determined by normalizing maximum isometric tetanic force to CSA.

\section{Statistical analysis}

Differences between samples were assessed by using the Student's two-tailed $t$ test for independent samples.

\section{Results}

\section{Rhabdomyosarcomas upon transplantation of MSCB9-Pax3 cells}

We have previously shown that Pax3 enables the commitment of a murine mesenchymal stem cell line toward the myogenic lineage in vitro [30]. We transplanted these cells into cardiotoxin-injured muscles of immunodeficient mice, and observed tumors arise by 4 weeks post-transplantation. These tumors were of donor origin, as evidenced by LacZ staining and GFP fluorescence (Figs. 1A, B). H\&E staining of these cryosections revealed cell death (necrosis) in abundance as well as a large number of small rounded cells characterized by large nuclei and little cytoplasm (Fig. 1A.ii, lower left panel). Pathological analyses of these samples classified these tumors as rhabdomyosarcomas. Indeed these very poorly differentiated neoplasms were positive for MyoD and Myogenin (Fig. 1B), a profile also characteristic of rhabdomyosarcoma [34-36]. Rhabdomyosarcomas (RMS) represent the most common soft tissue tumors affecting children and young adolescents, and can be sub-divided in two main categories, embryonal and alveolar. The latter is generally more aggressive and can be identified in most instances by the presence of the fusion oncogene Pax3/Forkhead or Pax7/Forkehead resulting from reciprocal chromosomal translocations [37,38]. Although we did not observe the development of tumors in mice injected with MSCB9-Vector control cells at 4 weeks (Fig. 1A.i) or at 8 weeks (Supplementary Fig. 1) after the transplantation, these cells were found at increasing levels as mononuclear cells in recipient muscles over time (Supplementary Fig. 1), suggesting they may eventually develop a tumor.

\section{PAX3 promotes the activation of the myogenic program in primary hMSCS}

To assess whether the generation of rhabdomyosarcoma in vivo was due specifically to Pax3 or a combinatory effect of Pax3 with the use of MSCB9, an immortalized cell line [39], we investigated next the ability of Pax3 to reprogram primary mesenchymal stem cells into myogenic progenitors, and whether these cells in vivo would develop rhabdomyosarcoma or produce muscle engraftment. For this purpose, we transduced Pax3 into primary mouse MSC preparations. Although these cells were amenable to

A
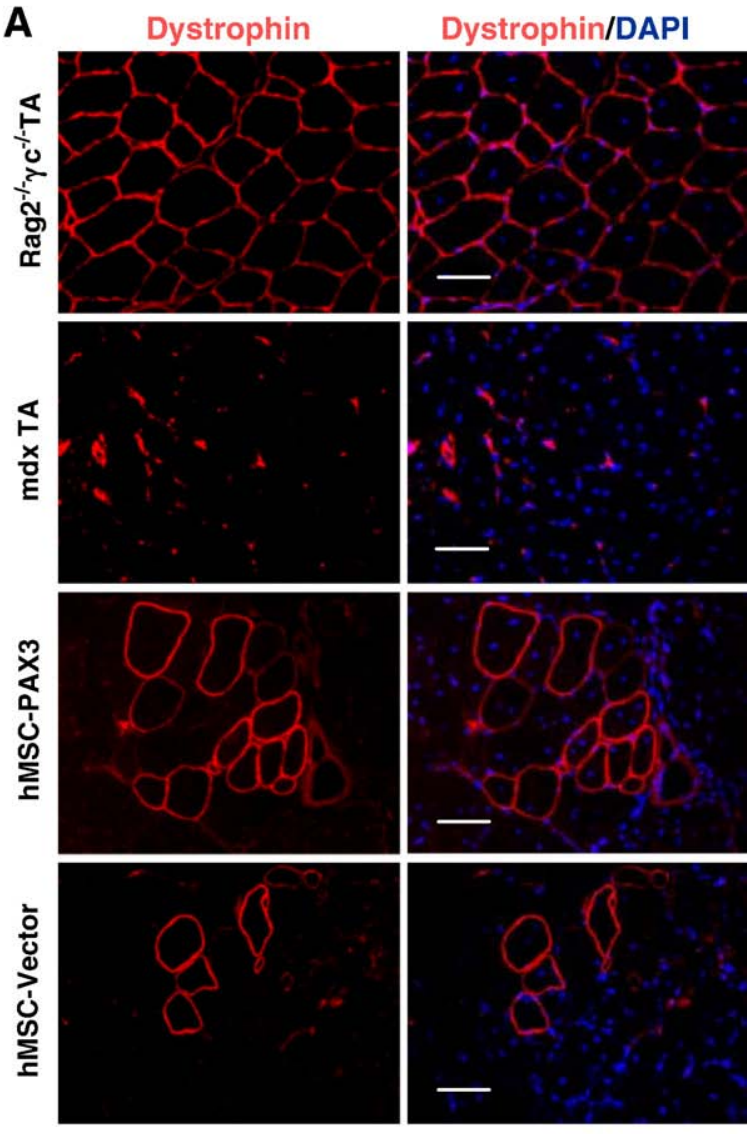

B

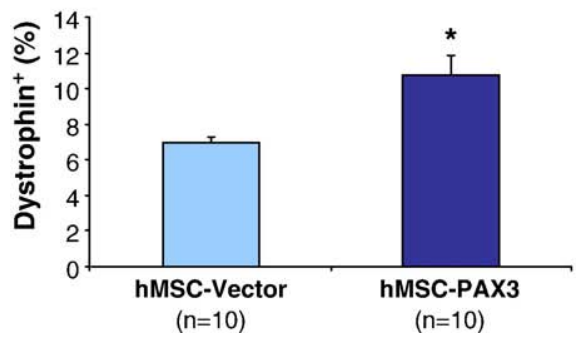

Fig. 5 - Engraftment of hMSCs is improved in the presence of PAX3. Human mesenchymal stem cell preparations transduced with PAX3 or Vector only were transplanted into tibialis anterior (TA) muscles from $\mathbf{m d x}$ mice that had been previously injured with cardiotoxin. (A) Dystrophin expression (in red) in wild-type mice (top row) and untreated $\mathrm{mdx}$ mice (second row). Third and fourth rows represent detection of dystrophin ${ }^{+}$ muscle fibers in $\mathbf{m d x}$ mice 4 weeks after transplantation with hMSC-PAX3 and hMSC-Vector cells, respectively. Scale bar is $100 \mu \mathrm{m}$. (B) Percentage of Dystrophin ${ }^{+}$myofibers per field in transplanted muscles. For each group, 80 high power fields $(200 \times)$ were selected and photographed at random areas, and myofiber number was recorded. The number in the parenthesis indicates the number of mice per group. $* P<0.01$. 
infection and MyoD could be detected in Pax3-transduced cultures (data not shown), after isolation, transduction, and sorting, cells were left with limited proliferative potential, with or without Pax3. This was probably due to the fact that cells were approaching senescence.

Based on these results, we decided to transduce primary human MSC preparations, which are known to grow much better than their mouse counterparts. Experiments were conducted with MSC preparations obtained from two independent human BM samples. Two days following lentiviral infection, both hMSC-PAX3 and control vector-transduced hMSC were FACS sorted for GFP ${ }^{+}$ cells (Fig. 2A, upper panel). In the presence of MSC expansion medium, both sorted cell fractions, hMSC-PAX3 and hMSC-Vector, proliferated at a similar rate and presented no apparent morphological differences (Fig. 2A, lower panel). Expression of PAX3 by hMSC-PAX3 but not hMSC-Vector cells was confirmed by immunofluorescent staining and Western blot analysis (Figs. 2B, C). Gene expression analyses for myogenic regulatory factors (MRFs) demonstrated up-regulation of MYOD in hMSC-PAX3 cultures (Fig. 2D). MYF5 and MYOGENIN, as well as MYOSIN HEAVY CHAIN $(M H C)$, a marker of terminal muscle differentiation, were barely detectable (Fig. 2D) under these expansion culture conditions. Both PAX3-transduced and control MSC preparations were negative for $\mathrm{CD} 45$ and $\mathrm{CD} 34$, while maintaining high expression levels of CD73, CD90, CD105, and CD44, a profile characteristic of MSCs (Fig. 3). The only antigen found to be expressed differentially in hMSC-PAX3 was CD56, a known marker for myogenic progenitors. While undetectable in hMSC-Vector cells, CD56 was up-regulated in PAX3-transduced MSCs (23.6\%; Fig. 3).

To test their muscle differentiation potential in vitro, we cultured hMSC-PAX3 and hMSC-Vector cells under several muscle inductive conditions (\#2,10\% FBS, bFGF, neuregulin, PDGF-AA and forskolin) [29]; \#3, 2\% HS [40], and \#4, 10\% FBS and 5-azacitidine for up to 4 weeks [26] (Fig. 4), along with control conditions, including basic MSC medium (\#1, 16.5\% FBS) [39], complete expansion medium (\#5, 10\% FBS and PDGF-BB/EGF) [39], and expansion medium without growth factors (\#6). This latter condition was investigated to assess whether growth factor withdrawal would allow the differentiation of hMSC-PAX3 and hMSC-Vector cells into myogenic cells. From all these conditions, myogenic differentiation was more prominent with medium containing bFGF, neuregulin, PDGF-AA and forskolin, and the induction medium containing 2\% HS (conditions 2 and 3 , respectively), as evidenced by gene expression analysis which revealed up-regulation of MYOD, MYF5, MYOGENIN, and to a lesser extent, MHC (Fig. 4B). Irrespective of the induction culture conditions, myogenic regulatory factors were scarcely detectable in hMSCs-Vector control cells. These results were corroborated by immunofluorescent staining for MYOD and MHC comparing hMSC-PAX3 to hMSCs-Vector cells (Fig. 4C), in the presence of proliferation (16.5\% FBS, \#1) and induction medium containing bFGF, neuregulin, PDGF-AA, and forskolin (\#2). The inductive differentiation condition (\#2) resulted in the generation of MYOD ${ }^{+}$ and $\mathrm{MHC}^{+}$cells $(23.84 \% \pm 3.22 \%$ and $4.5 \% \% \pm 1.7 \%$, respectively), with a fusion index of $3.1 \% \pm 1.8 \%$.

\section{PAX3-modified primary human MSCs do not generate rhabdomyosarcomas in vivo}

To test the myogenic differentiation potential of hMSC-PAX3 cells in vivo, we initially transplanted these cells as well as hMSC-Vector control cells into the TA muscles of CTX-injured Rag2-/- $\gamma \mathrm{c}^{-/-}$ immunodeficient mice. At 8 weeks post-transplantation rather than rhabdomyosarcoma, as previously observed with MSCB9-
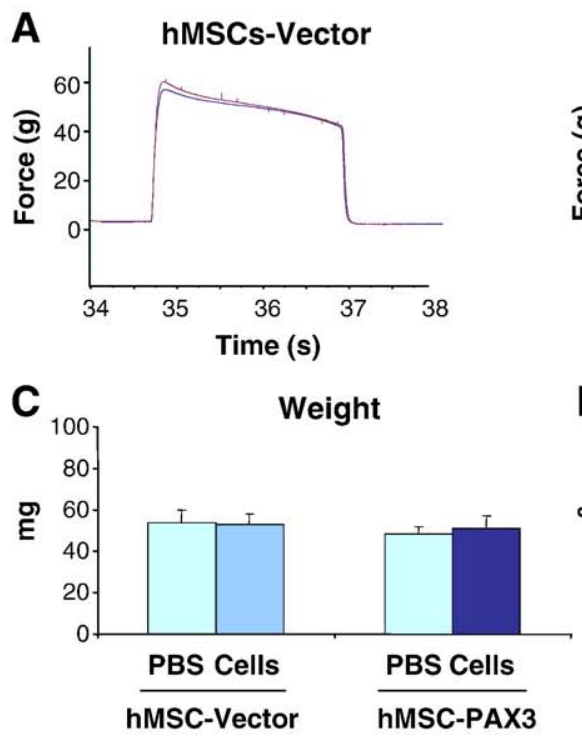
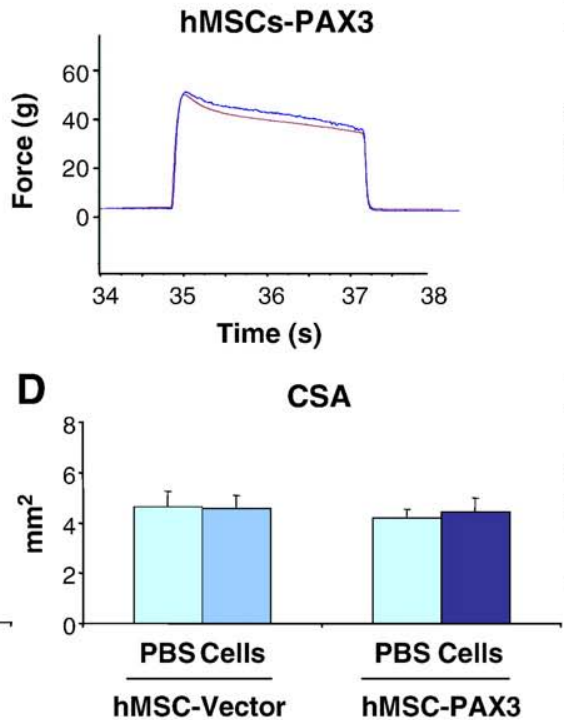
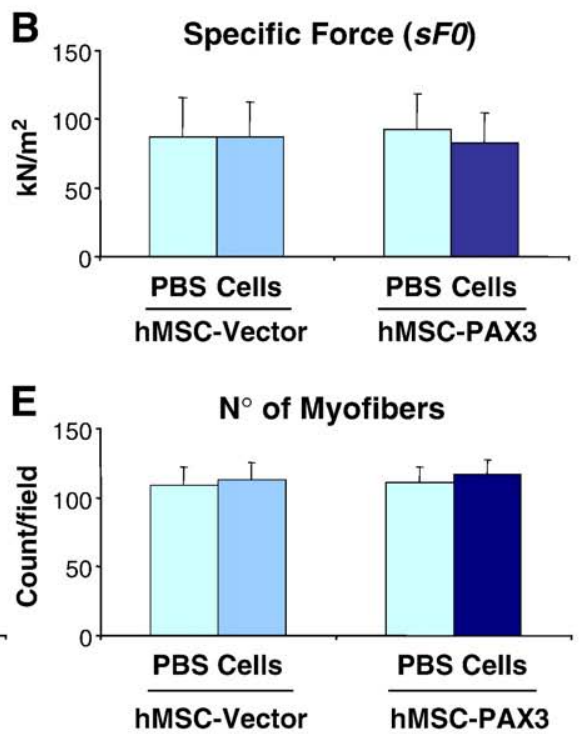

Fig. 6 - MSCs fail to promote in vivo functional recovery. Values shown are the results of 3 independent experiments on a total of 14 mice per group \pm SEM. (A) Representative example of force tracing in TA muscles from hMSC-Vector- (left) and hMSC-PAX3- (right) transplanted $m d x$ mice. Blue and red lines show force tracing from muscles that had received cell transplantation or PBS (control), respectively. Muscles at $L_{0}$ were stimulated for $2 \mathrm{~s}$ with a $150 \mathrm{~Hz}, 25 \mathrm{~V}, 0.2 \mathrm{~ms}$ square pulse and isometric tetanic force was recorded. (B) Effect of cell transplantation on specific force $\left(s F_{0}: F_{0}\right.$ normalized to CSA). (C, D) Average weight and CSA, respectively. (E) Number of myofibers per field in analyzed muscles. For each group, 10 high power fields (100x) selected at random were photographed and myofiber number was recorded in a blinded fashion by 2 independent investigators. 
Pax3 cells (Fig. 1), we detected the presence of $\mathrm{GFP}^{+}$muscle fibers (data not shown). The fact that PAX3-transduced primary human MSCs did not result in rhabdomyosarcoma formation in vivo suggests that Pax3 per se does not lead to muscle tumor, only when used in combination with an immortalized cell line.

To evaluate whether these cells have the ability to restore dystrophin expression in $m d x$ mice, we injected either PAX3transduced or Vector control MSCs into CTX-injured TA muscles. As an internal control, contralateral TA muscle was injected with the same volume $(50 \mu \mathrm{l})$ of PBS. Four weeks later, dystrophin expression was observed in both groups receiving cell transplantation, although more clusters of dystrophin ${ }^{+}$myofibers were detected in hMSC-PAX3 than their vector control group (11\% versus 7\%; Figs. 5A, B).

\section{Restored dystrophin expression is not accompanied by functional recovery}

Finally, to assess whether cell engraftment would result in an improvement in muscle function, we measured the contractile properties of TA muscles from $m d x$ mice following the transplantation of hMSC-PAX3 or hMSC-Vector cultures. Both groups showed similar isometric tetanic force (Fig. 6A) and specific force (Fig. 6B) when compared to their control counterparts. Accordingly, there were no changes in muscle weight (Fig. 6C), CSA (Fig. 6D), or numbers of myofibers between PBS- and celltransplanted muscles (Fig. 6E). These results suggest that engraftment by MSCs is not sufficient to trigger functional improvement of dystrophic muscles.

\section{Discussion}

A growing body of evidence suggests that cell-based therapies might be beneficial for the treatment of neuromuscular conditions. Encouraging results have been obtained following the transplantation of several stem cell preparations [29,41-48] into mouse models of muscular dystrophy. Although most of these studies comprise cell populations isolated directly from muscle tissues, such as satellite cells and mesoangioblasts, stromal cells from bone marrow [29] and adipose tissues [46,47] have also been attributed with in vivo muscle regenerative potential.

In terms of cells isolated from bone marrow, in vivo skeletal muscle regeneration has been observed with human MSCs genetically manipulated with activated Notch [29]. Engraftment of these human cells was observed following their intramuscular or intravenous injection into immunosuppressed rats as well as into immunodeficient dystrophic ( $m d x$-nude) mice previously injured with cardiotoxin (CTX) [29]. The ratio of donor-derived myofibers $\left(\mathrm{GFP}^{+}\right)$in engrafted muscles varied between $14.7 \%$ and $50.9 \%$. Although muscle function was not investigated, with such levels of chimerism, one would expect improvement in muscle function following the transplantation of these cells. The mechanism by which activated Notch acts in this study is unclear since this gene is well recognized for its repressive effect on myogenic determination [49-52].

We have demonstrated that Pax3, an essential transcription factor for embryonic muscle specification [53-56], enables the generation of early skeletal muscle progenitors from differentiating mouse embryonic stem cells [57]. Upon local and systemic transplantation into $m d x$ mice, these cells produce substantial engraftment of adult myofibers, which are endowed with superior contractile function [57]. In order to assess whether Pax3 would enable the reprogramming of adult cells towards the myogenic lineage, we began by extending this approach to a mesenchymal stem cell line (MSCB9) derived from adult mouse bone marrow [39]. As recently reported, Pax3 allowed the activation of the myogenic program in these cells, which occurred at the expense of their differentiation into fat, bone, and cartilage tissues [30]. This effect appears cell type-selective since overexpression of Pax3 in endothelial cells failed to promote the activation of the myogenic program [30].

Here we show that transplantation of Pax3-transduced MSCB9 cell preparations into CTX-injured skeletal muscles of immunodeficient mice leads to the development of muscle tumors, resembling rhabdomyosarcomas [34-36]. Most alveolar rhabdomyosarcomas (ARMS) are characterized by the presence of a translocation-mediated fusion of Pax3 or Pax7 to a Fkhr gene, $\mathrm{t}$ $(2 ; 13)$ and $\mathrm{t}(1 ; 13)$, respectively. Pax3/Fkhr fusion gene is more common, being detected in 55\%-75\% of ARMS cases [37,38,58,59]. Nevertheless, both Pax3/Fkhr and Pax7/Fkhr fusion proteins are strong transcriptional activators and are thought to play a crucial role in the origin of ARMS by interfering with the muscle development program. Since transplantation of Pax3-transduced primary MSCs did not generate tumors, our studies demonstrate that ARMS-like tumors were not solely due to Pax3 but a combination of Pax3 and mutations acquired by MSCB9, an immortalized cell line with karyotypic abnormalities [39]. Interestingly, successful generation of a mouse model for ARMS was obtained only when combining conditional expression of Pax3/ Fkhr with Ink4a/ARF and Trp53 loss of function [36]. Previous transgenic mice expressing only Pax3/Fkhr showed aberrant myogenesis but no tumor formation [60,61]. Additional mutations probably play a role in ARMS by providing a growth advantage to affected cells.

Our in vitro data with primary human MSCs show that PAX3 indeed has the ability to activate the myogenic program in MSCs, although to a lesser extent than observed with the MSCB9 cell line [30]. Importantly, transplantation of PAX3-transduced primary human MSC preparations produces muscle engraftment, rather than muscle tumors. However engraftment into $m d x$ mice is not accompanied by functional recovery, as evidenced by measuring the contractility force of engrafted muscles. It is possible that the levels of engraftment obtained here $(10.8+3.6 \%)$ are not enough to trigger functional improvement. As discussed above, high levels of engraftment have been obtained following the transplantation of human MSCs transduced with activated Notch into CTX-injured immunosuppressed rats and mdx-nude mice [29] but to date, functional measurements have not been documented. It may also be the case that human-derived myofibers have impaired function in the mouse environment. Nonetheless, reports of improvement in muscle function following the transplantation of specific human cell populations have been described using the scid/mdx mouse model $[48,62]$.

A recent study by Rose et al. has shown that although bone marrow-derived MSCs can be induced to adopt a cardiac muscle phenotype, by expressing cardiac-specific makers, they still retain the MSC phenotype and fail to become functional cardiomyocytes in vitro [63]. The same may be the case here since PAX3-transduced hMSCs still maintain a MSC phenotype (Fig. 3), despite expression of MYOD and CD56. These results suggest that the presence of 
Dystrophin $^{+}$myofibers in transplanted mice may result exclusively from fusion of donor cells with resident myofibers rather than from the reprogramming of MSCs into myogenic progenitors. This hypothesis is reinforced by the lack of evidence that hMSCPax3 cells contribute to the satellite cell compartment in vivo (persona). If this is the case, it is possible that multiple cell injections might be necessary in order to trigger functional improvement of dystrophic muscles by MSC therapy. Thus further development is necessary in order to overcome the limitations associated with the therapeutic application of MSC preparations for muscular dystrophies.

\section{Acknowledgments}

This work was supported by the Dr. Bob and Jean Smith Foundation. We thank Diego H. Castrillon for pathology expertise. The monoclonal antibody to MHC was obtained from the Developmental Studies Hybridoma Bank developed under the auspices of the NICHD and maintained by the University of Iowa.

\section{Appendix A. Supplementary data}

Supplementary data associated with this article can be found, in the online version, at doi:10.1016/j.yexcr.2009.05.009.

\section{REFERENCES}

[1] E.P. Hoffman, R.H.J. Brown, L.M. Kunkel, Dystrophin: the protein product of the Duchenne muscular dystrophy locus, Cell 51 (1987) 919-928.

[2] M. Koenig, E.P. Hoffman, C.J. Bertelson, A.P. Monaco, C. Feener, L.M. Kunkel, Complete cloning of the Duchenne muscular dystrophy (DMD) cDNA and preliminary genomic organization of the DMD gene in normal and affected individuals, Cell 50 (1987) 509-517.

[3] R. Nawrotzki, D.J. Blake, K.E. Davies, The genetic basis of neuromuscular disorders. Trends Genet. 12 (1996) 294-298.

[4] B.E. Petersen, W.C. Bowen, K.D. Patrene, W.M. Mars, A.K. Sullivan, N. Murase, S.S. Boggs, J.S. Greenberger, J.P. Goff, Bone marrow as a potential source of hepatic oval cells, Science 284 (1999) $1168-1170$.

[5] T.R. Brazelton, F.M. Rossi, G.I. Keshet, H.M. Blau, From marrow to brain: expression of neuronal phenotypes in adult mice, Science 290 (2000) 1775-1779.

[6] T. Ito, A. Suzuki, M. Okabe, E. Imai, M. Hori, Application of bone marrow-derived stem cells in experimental nephrology, Exp. Nephrol. 9 (2001) 444-450.

[7] D. Orlic, J. Kajstura, S. Chimenti, I. Jakoniuk, S.M. Anderson, B. Li, J. Pickel, R. McKay, B. Nadal-Ginard, D.M. Bodine, A. Leri, P. Anversa, Bone marrow cells regenerate infarcted myocardium, Nature 410 (2001) 701-705.

[8] E. Lagasse, H. Connors, M. Al-Dhalimy, M. Reitsma, M. Dohse, L. Osborne, X. Wang, M. Finegold, I.L. Weissman, M. Grompe, Purified hematopoietic stem cells can differentiate into hepatocytes in vivo, Nat. Med. 11 (2000) 1229-1234.

[9] D. Hess, L. Li, M. Martin, S. Sakano, D. Hill, B. Strutt, S. Thyssen, D.A. Gray, M. Bhatia, Bone marrow-derived stem cells initiate pancreatic regeneration, Nat. Biotechnol. 21 (2003) 763-770.

[10] G. Ferrari, G. Cusella-De Angelis, M. Coletta, E. Paolucci, A. Stornaiuolo, G. Cossu, F. Mavilio, Muscle regeneration by bone marrow-derived myogenic progenitors, Science 279 (1998) 1528-1530.
[11] E. Gussoni, Y. Soneoka, C.D. Strickland, E.A. Buzney, M.K. Khan, A.F. Flint, L.M. Kunkel, R.C. Mulligan, Dystrophin expression in the mdx mouse restored by stem cell transplantation, Nature 401 (1999) 390-394.

[12] R.E. Bittner, C. Schofer, K. Weipoltshammer, S. Ivanova, B. Streubel, E. Hauser, M. Freilinger, H. Hoger, A. Elbe-Burger, F. Wachtler, Recruitment of bone-marrow-derived cells by skeletal and cardiac muscle in adult dystrophic mdx mice, Anat. Embryol. (Berl). 199 (1999) 391-396.

[13] S. Fukada, Y. Miyagoe-Suzuki, H. Tsukihara, K. Yuasa, S. Higuchi, S. Ono, K. Tsujikawa, S. Takeda, H. Yamamoto, Muscle regeneration by reconstitution with bone marrow or fetal liver cells from green fluorescent protein-gene transgenic mice, J. Cell Sci. 115 (2002) 1285-1293.

[14] M. Abedi, D.A. Greer, B.M. Foster, G.A. Colvin, J.A. Harpel, D.A. Demers, J. Pimentel, M.S. Dooner, P.J. Quesenberry, Critical variables in the conversion of marrow cells to skeletal muscle, Blood 106 (2005) 1488-1494.

[15] P. Bossolasco, S. Corti, S. Strazzer, C. Borsotti, R. Del Bo, F. Fortunato, S. Salani, N. Quirici, F. Bertolini, A. Gobbi, G.L. Deliliers, G. Pietro Comi, D. Soligo, Skeletal muscle differentiation potential of human adult bone marrow cells. Exp. Cell Res. 295 (2004) 66-78.

[16] G. Ferrari, A. Stornaiuolo, F. Mavilio, Failure to correct murine muscular dystrophy, Nature 411 (2001) 1014-1015.

[17] M. Alvarez-Dolado, R. Pardal, J.M. Garcia-Verdugo, J.R. Fike, H.O. Lee, K. Pfeffer, C. Lois, S.J. Morrison, A. Alvarez-Buylla, Fusion of bone-marrow-derived cells with Purkinje neurons, cardiomyocytes and hepatocytes, Nature 425 (2003) 968-973.

[18] R.F. Castro, K.A. Jackson, M.A. Goodell, C.S. Robertson, H. Liu, H.D. Shine, Failure of bone marrow cells to transdifferentiate into neural cells in vivo, Science 297 (2002) 1299.

[19] J.M. Nygren, S. Jovinge, M. Breitbach, P. Säwén, W. Röll, J. Hescheler, J. Taneera, B.K. Fleischmann, S.E. Jacobsen, Bone marrow-derived hematopoietic cells generate cardiomyocytes at a low frequency through cell fusion, but not transdifferentiation, Nat. Med. 10 (2004) 494-501.

[20] X. Wang, H. Willenbring, Y. Akkari, Y. Torimaru, M. Foster, M. Al-Dhalimy, E. Lagasse, M. Finegold, S. Olson, M. Grompe, Cell fusion is the principal source of bone-marrow-derived hepatocytes, Nature 422 (2003) 897-901.

[21] L.B. Balsam, A.J. Wagers, J.L. Christensen, T. Kofidis, I.L. Weissman, R.C. Robbins, Haematopoietic stem cells adopt mature haematopoietic fates in ischaemic myocardium, Nature 428 (2004) 668-673.

[22] C.E. Murry, M.H. Soonpaa, H. Reinecke, H. Nakajima, H.O. Nakajima, M. Rubart, K.B. Pasumarthi, J.I. Virag, S.H. Bartelmez, V. Poppa, G. Bradford, J.D. Dowell, D.A. Williams, L.J. Field, Haematopoietic stem cells do not transdifferentiate into cardiac myocytes in myocardial infarcts, Nature 428 (2004) 664-668.

[23] R.F. Pereira, K.W. Halford, M.D. O'Hara, D.B. Leeper, B.P. Sokolov, M.D. Pollard, O. Bagasra, D.J. Prockop, Cultured adherent cells from marrow can serve as long-lasting precursor cells for bone, cartilage, and lung in irradiated mice, Proc. Natl. Acad. Sci. U. S. A. 92 (1995) 4857-4861.

[24] D.J. Prockop, Marrow stromal cells as stem cells for nonhematopoietic tissues, Science 276 (1997) 71-74.

[25] M.F. Pittenger, A.M. Mackay, S.C. Beck, R.K. Jaiswal, R. Douglas, J.D. Mosca, M.A. Moorman, D.W. Simonetti, S. Craig, D.R. Marshak, Multilineage potential of adult human mesenchymal stem cells, Science 284 (1999) 143-147.

[26] S.T. Wakitani, S. Caplan, A.I., , Myogenic cells derived from rat bone marrow mesenchymal stem cells exposed to 5-azacytidine, Muscle Nerve 18 (1995) 1417-1426.

[27] T. Saito, J.E. Dennis, D.P. Lennon, R.G. Young, A.I. Caplan, Myogenic expression of mesenchymal stem cells within myotubes of $\mathrm{mdx}$ mice in vitro and in vivo, Tissue Eng. 1 (1995) 327-343.

[28] J. Chan, K. O'Donoghue, M. Gavina, Y. Torrente, N. Kennea, H. 
Mehmet, H. Stewart, D.J. Watt, J.E. Morgan, N.M. Fisk, Galectin-1 induces skeletal muscle differentiation in human fetal mesenchymal stem cells and increases muscle regeneration, Stem Cells 24 (2006) 1879-1891.

[29] M. Dezawa, H. Ishikawa, Y. Itokazu, T. Yoshihara, M. Hoshino, S. Takeda, C. Ide, Y. Nabeshima, Bone marrow stromal cells generate muscle cells and repair muscle degeneration, Science 309 (2005) 314-317.

[30] E.J. Gang, D. Bosnakovski, T. Simsek, K. To, R.C.R. Perlingeiro, Pax3 activation promotes the differentiation of mesenchymal stem cells toward the myogenic lineage, Exp. Cell Res. (2008) doi: 10.1016/j.yexcr.2008.02.016.

[31] M. Kyba, R.C. Perlingeiro, G.Q. Daley, HoxB4 confers definitive lymphoid-myeloid engraftment potential on embryonic stem cell and yolk sac hematopoietic progenitors, Cell 109 (2002) 29-37.

[32] C. Lois, E.J. Hong, S. Pease, E.J. Brown, D. Baltimore, Germline transmission and tissue-specific expression of transgenes delivered by lentiviral vectors, Science 295 (2002) 868-872.

[33] M. Wijker, N.V. Morgan, S. Herterich, C.G. van Berkel, A.J. Tipping, H.J. Gross, J.J. Gille, G. Pals, M. Savino, C. Altay, S. Mohan, I. Dokal, J. Cavenagh, J. Marsh, M. van Weel, J.J. Ortega, D. Schuler, E. Samochatova, M. Karwacki, A.N. Bekassy, M. Abecasis, W. Ebell, M.L. Kwee, T. de Ravel, C.G. Mathew, Heterogeneous spectrum of mutations in the Fanconi anaemia group A gene, Eur. J. Hum. Genet. 7 (1999) 52-59.

[34] J. Khan, R. Simon, M. Bittner, Y. Chen, S.B. Leighton, T. Pohida, P.D. Smith, Y. Jiang, G.C. Gooden, J.M. Trent, P.S. Meltzer, Gene expression profiling of alveolar rhabdomyosarcoma with cDNA microarrays, Cancer Res. 58 (1998) 5009-5013.

[35] N.J. Sebire, M. Malone, Myogenin and MyoD1 expression in paediatric rhabdomyosarcomas, J. Clin. Pathol. 56 (2003) 412-416.

[36] C. Keller, B.R. Arenkiel, C.M. Coffin, N. El-Bardeesy, R.A. DePinho, M.R. Capecchi, Alveolar rhabdomyosarcomas in conditional Pax3: Fkhr mice: cooperativity of Ink4a/ARF and Trp53 loss of function, Genes Dev. 18 (2004) 2614-2626.

[37] N. Galili, R.J. Davis, W.J. Fredericks, S. Mukhopadhyay, F.J.r. Rauscher, B.S. Emanuel, G. Rovera, F.G. Barr, Fusion of a fork head domain gene to PAX3 in the solid tumour alveolar rhabdomyosarcoma, Nat. Genet. 5 (1993) 230-235.

[38] R.J. Davis, C.M. D'Cruz, M.A. Lovell, J.A. Biegel, F.G. Barr, Fusion of PAX7 to FKHR by the variant $t(1 ; 13)$ (p36;q14) translocation in alveolar rhabdomyosarcoma, Cancer Res. 54 (1994) 2869-2872.

[39] E.J. Gang, D. Bosnakovski, C.A. Figueiredo, J.W. Visser, R.C.R. Perlingeiro, SSEA-4 identifies mesenchymal stem cells from bone marrow, Blood 109 (2007) 1743-1751.

[40] L.A. Megeney, B. Kablar, K. Garrett, J.E. Anderson, M.A. Rudnicki, MyoD is required for myogenic stem cell function in adult skeletal muscle, Genes Dev. 10 (1996) 1173-1183.

[41] D. Montarras, J. Morgan, C. Collins, F. Relaix, S. Zaffran, A. Cumano, T. Partridge, M. Buckingham, Direct isolation of satellite cells for skeletal muscle regeneration, Science 309 (2005) 2064-2067.

[42] R.I. Sherwood, J.L. Christensen, I.M. Conboy, M.J. Conboy, T.A. Rando, I.L. Weissman, A.J. Wagers, Isolation of adult mouse myogenic progenitors: functional heterogeneity of cells within and engrafting skeletal muscle, Cell 119 (2004) 543-554.

[43] Z. Qu-Petersen, B. Deasy, R. Jankowski, M. Ikezawa, J. Cummins, R. Pruchnic, J. Mytinger, B. Cao, C. Gates, A. Wernig, J. Huard, Identification of a novel population of muscle stem cells in mice: potential for muscle regeneration, J. Cell Biol. 157 (2002) 851-864.

[44] M. Sampaolesi, Y. Torrente, A. Innocenzi, R. Tonlorenzi, G. D'Antona, M.A. Pellegrino, R. Barresi, N. Bresolin, M.G. De Angelis, K.P. Campbell, R. Bottinelli, G. Cossu, Cell therapy of alpha-sarcoglycan null dystrophic mice through intra-arterial delivery of mesoangioblasts, Science 301 (2003) 487-492.

[45] M. Cerletti, S. Jurga, C.A. Witczak, M.F. Hirshman, J.L. Shadrach, L.J. Goodyear, A.J. Wagers, Highly efficient, functional engraftment of skeletal muscle stem cells in dystrophic muscles, Cell 134 (2008) 37-47.

[46] N.M. Vieira, C.R.J. Bueno, V. Brandalise, L.V. Moraes, E. Zucconi, M. Secco, M.F. Suzuki, M.M. Camargo, P. Bartolini, P.C. Brum, M. Vainzof, M. Zatz, Sjl dystrophic mice express a significant amount of human muscle proteins following systemic delivery of human adipose-derived stromal cells without immunosuppression, Stem Cells (2008) [electronic publication ahead of print].

[47] A.M. Rodriguez, D. Pisani, C.A. Dechesne, C. Turc-Carel, J.Y. Kurzenne, B. Wdziekonski, A. Villageois, C. Bagnis, J.P. Breittmayer, H. Groux, G. Ailhaud, C. Dani, Transplantation of a multipotent cell population from human adipose tissue induces dystrophin expression in the immunocompetent mdx mouse, J. Exp. Med. 201 (2005) 1397-1405.

[48] Y. Torrente, M. Belicchi, M. Sampaolesi, F. Pisati, M. Meregalli, G. D'Antona, R. Tonlorenzi, L. Porretti, M. Gavina, K. Mamchaoui, M.A. Pellegrino, D. Furling, V. Mouly, G.S. Butler-Browne, R. Bottinelli, G. Cossu, N. Bresolin, Human circulating AC133(+) stem cells restore dystrophin expression and ameliorate function in dystrophic skeletal muscle, J. Clin. Invest. 114 (2004) 182-195.

[49] R. Kopan, J.S. Nye, H. Weintraub, The intracellular domain of mouse Notch: a constitutively activated repressor of myogenesis directed at the basic helix-loop-helix region of MyoD, Development 120 (1994) 2385-2396.

[50] J. Wilson-Rawls, J.D. Molkentin, B.L. Black, E.N. Olson, Activated notch inhibits myogenic activity of the MADS-Box transcription factor myocyte enhancer factor 2C, Mol. Cell. Biol. 19 (1999) 2853-2862.

[51] D. Nofziger, A. Miyamoto, K.M. Lyons, G. Weinmaster, Notch signaling imposes two distinct blocks in the differentiation of C2C12 myoblasts, Development 126 (1999) 1689-1702.

[52] T. Kitamura, Y.I. Kitamura, Y. Funahashi, C.J. Shawber, D.H. Castrillon, R. Kollipara, R.A. DePinho, J. Kitajewski, D. Accili, A Foxo/Notch pathway controls myogenic differentiation and fiber type specification, J. Clin. Invest. 117 (2007) 2477-2485.

[53] L. Kassar-Duchossoy, E. Giacone, B. Gayraud-Morel, A. Jory, D. Gomes, S. Tajbakhsh, Pax3/Pax7 mark a novel population of primitive myogenic cells during development, Genes Dev. 19 (2005) 1426-1431.

[54] F. Relaix, D. Rocancourt, A. Mansouri, M. Buckingham, A Pax3/Pax7-dependent population of skeletal muscle progenitor cells, Nature 435 (2005) 948-953.

[55] M. Goulding, A. Lumsden, A.J. Paquette, Regulation of Pax-3 expression in the dermomyotome and its role in muscle development, Development 120 (1994) 957-971.

[56] J.P. Tremblay, S. Dietrich, M. Mericskay, F.R. Scubert, Z. Li, D. Paulin, A crucial role for Pax3 in the development of the hypaxial musculature and the long-range migration of muscle precursors, Dev. Biol. 203 (1998) 49-61.

[57] R. Darabi, K. Gehlbach, R.M. Bachoo, S. Kamath, M. Osawa, K.E. Kamm, M. Kyba, R.C. Perlingeiro, Functional skeletal muscle regeneration from differentiating embryonic stem cells. Nat. Med. 14 (2008) 134-143.

[58] F.G. Barr, N. Galili, J. Holick, J.A. Biegel, G. Rovera, B.S. Emanuel, Rearrangement of the PAX3 paired box gene in the paediatric solid tumour alveolar rhabdomyosarcoma, Nat. Genet. 3 (1993) 113-117.

[59] P.H. Sorensen, J.C. Lynch, S.J. Qualman, R. Tirabosco, J.F. Lim, H.M. Maurer, J.A. Bridge, W.M. Crist, T.J. Triche, F.G. Barr, PAX3-FKHR and PAX7-FKHR gene fusions are prognostic indicators in alveolar rhabdomyosarcoma: a report from the children's oncology group, J. Clin. Oncol. 20 (2002) 2672-2679.

[60] I. Lagutina, S.J. Conway, J. Sublett, G.C. Grosveld, Pax3-FKHR knock-in mice show developmental aberrations but do not develop tumors, Mol. Cell. Biol. 22 (2002) 7204-7216.

[61] F.G. Finckenstein, E. Davicioni, K.G. Osborn, W.K. Cavenee, K.C. Arden, M.J. Anderson, Transgenic mice expressing PAX3-FKHR have multiple defects in muscle development, including ectopic skeletal myogenesis in the developing neural tube, Transgenic Res. 15 (2006) 595-614. 
[62] A. Dellavalle, M. Sampaolesi, R. Tonlorenzi, E. Tagliafico, B. Sacchetti, L. Perani, A. Innocenzi, B.G. Galvez, G. Messina, R. Morosetti, S. Li, M. Belicchi, G. Peretti, J.S. Chamberlain, W.E. Wright, Y. Torrente, S. Ferrari, P. Bianco, G. Cossu, Pericytes of human skeletal muscle are myogenic precursors distinct from satellite cells, Nat. Cell Biol. 9 (2007) 255-267.
[63] R.A. Rose, H. Jiang, X. Wang, S. Helke, J.N. Tsoporis, N. Gong, S.C. Keating, T.G. Parker, P.H. Backx, A. Keating, Bone marrow-derived mesenchymal stromal cells express cardiac- specific markers, retain the stromal phenotype and do not become functional cardiomyocytes in vitro, Stem Cells 26 (2008) 2884-2892.

Please cite this article as: E.J. Gang, et al., Engraftment of mesenchymal stem cells into dystrophin-deficient mice is not accompanied by functional recovery, Exp. Cell Res. (2009), doi:10.1016/j.yexcr.2009.05.009 